\title{
Transforming the Built Environment Through Healthy-Design Strategies
}

\section{A Multidimensional Framework for Urban Plans' Evaluation}

\author{
Maddalena Buffoli $^{1}$ (D), Andrea Rebecchi ${ }^{1}$ (D), Marta Dell'Ovo ${ }^{1}$ (D), \\ Alessandra Oppio $^{2(\bowtie)}(\mathbb{D})$, and Stefano Capolongo ${ }^{1}(\mathbb{D}$ \\ ${ }^{1}$ Department of Architecture, Built Environment and Construction Engineering \\ (ABC), Politecnico di Milano, via G. Ponzio 31, 20133 Milan, Italy \\ \{maddalena. buffoli, andrea. rebecchi, marta. dellovo, \\ stefano.capolongo\}@polimi.it \\ 2 Department of Architecture and Urban Studies (DAStU), Politecnico di \\ Milano, via E. Bonardi 3, 20133 Milan, Italy \\ alessandra.oppio@polimi.it
}

\begin{abstract}
According to the research grant titled "Urban Health: good practices for health impact assessment of urban and environmental redevelopment and regeneration interventions" and awarded by the Italian National Center for Disease prevention and Control (CCM) in 2017, this paper is aimed to describe the overall goal of the project: develop and disseminate experience-based practices among Policy Makers, based on Health Impact Assessment models, literature and case studies, mainly referred to healthy aging and equity in urban regeneration programs. The authors were involved in the development and application phases of a quali-quantitative assessment tool, capable of providing an effective and flexible support to the Local Health Agencies (LHAs) for evaluating the Urban Health strategies' integrations into urban plans.

The final framework is composed by 20 criteria, aimed to assess the propensity of urban plans to promote Urban Health strategies. The criteria are divided into 7 macro-areas: the first one including prerequisites $(0$. General criteria) while the other 6 constituting the assessment tool (1. Environment; 2. Soil and subsoil; 3. Sustainability and hygiene of the built environment; 4. Urban and social development; 5. Mobility and transport; 6. Outdoor spaces).

This research project could be considered a starting point to disseminate methods, tools and indicators to design and assess not merely the public spaces' environmental quality, but also foresee the urban plans' Public Health outcomes.
\end{abstract}

Keywords: Urban Health · Urban assessment tool · Healthy and sustainable environment 


\section{Theoretical Scenario}

\subsection{State of the Art}

The relations between the morpho-typological and functional features of the built environment and Public Health outcomes, open to a challenging scenario about the Urban Health research topic, considering the huge urbanization phenomena that characterizes contemporary cities and societies, both at european level than in developing countries. The United Nations (UN) Population Division Department states that today $54 \%$ of the world's population live in urban areas. This is expected to rise up to $70 \%$ by 2050 , when the World's urban population will exceed 6 billion [1]. The increase of buildings density will be one of the main global trends, with significant impacts connected to the increase of environmental risk factors (Urban Heat Island Effect; soil, air, acoustic and light pollution, in terms of inappropriate artificial lighting devices and low natural lighting of places; vehicular traffic conditions; urban safety \& security; poor attractiveness of places) affecting the contemporary cities [2], creating a gap between an healthy environment and alarming living conditions.

Referring to the Agenda 2030, the Sustainable Development Goals (SDG's) highlighted how cities today represent the most challenging context for quality of life, environmental sustainability, health and social inclusion and their strategic role in adapting to climate change. In particular, the 11th SDGs argue about "Sustainable Cities and Communities" [3] and state how urban development and renewal initiatives should be designed and organized to make cities healthier, smarter, resilient, safe and circular.

To summarize these concepts, the meaningful synthesis of the challenging relationship between urban planning and Public Health was recently stated by World Health Organization [4] into the following sentence: "Health is the precondition of urban sustainable development and the first priority for urban planners".

In this scenario, in the last years, researchers and practitioners, both of technical and medical education, identified the need of inter-disciplinary approaches, in order to address the cities' key features to Public Health outcomes [5]. There's a need of joint actions in order to involve the communities [6], starting from the professionals themselves. Urban Health strategies should be considered since the early stages of urban planning [7], as vehicles of primary health prevention and promotion [8].

In order to promote health in urban areas through urban planning strategies, a first research was conducted in 2010 by Politecnico di Milano in collaboration with the Local Health Agency (LHA) of the Municipality of Milano (better known as ASL Milano, but nowadays called ATS Città Metropolitana di Milano). However, the new, emerging and disruptive environmental risk factors (i.e. Climate Change) together with the contemporary Public Health needs, such as social inclusion, equity, safety and Design for All, have highlighted the critical issues and the irrelevance of the strategies developed previously. 


\subsection{Research Opportunities}

According to this scientific debate, the authors are part of a research group at Department of Architecture, Built environment and Construction engineering (ABC) of Politecnico di Milano still working on a research grant titled "Urban Health: good practices for health impact assessment of urban and environmental redevelopment and regeneration interventions" and awarded in 2017 by the Italian National Center for Disease prevention and Control (CCM). The overall goal of the research project CCM2017 was to develop and disseminate experience-based practices among Policy Makers, based on Health Impact Assessment models, literature and case studies, mainly referred to healthy aging and equity in urban regeneration programs.

The specific objectives of the CCM2017 project were six; the key one - the first was to draft and apply a quali-quantitative assessment tool, capable of providing an effective and flexible support to the LHAs for evaluating the Urban Health strategies' integrations into urban plans. Even before the research proposal, it was highlighted the lack - in the national scenario - of evaluation tools capable to support, both designers and Policy Makers, in the achievement of Public Health purposes [9].

\section{Methodological Framework}

Given these premises and according to the experience developed in 2010 by Politecnico di Milano together with the LHA of the Municipality of Milano (better known as ASL Milano, but nowadays called ATS Città Metropolitana di Milano), the current research provided a deep revision of the overall structure of the tool previously framed by solving and implementing criticalities detected by its application and given the necessity to update the methodology and the contents.

The research developed in 2010 was divided into criteria too, but with a different purpose: in 2010 the objective was to evaluate the environmental hygiene aspects of urban plans; actually, the tool presented in this paper, aims to assess the level of adherence and development of the Urban Health criteria. Furthermore, in the current tool, the criteria are weighted according to importance and therefore contribute, in a different way, to the final score.

The final goal of the research is to define a quali-quantitative assessment tool, capable of providing effective and flexible support to the LHAs for evaluating the Urban Health strategies' integrations into urban plans. For this reason, the methodological framework has been divided mainly in 3 phases organized by following the scheme of [10] namely intelligence, design and choice (Fig. 1), that can be described as follow:

- the intelligence phase refers to the description of the main objectives, the analysis of the previous experience and a deep investigation of the state of the art.

- the design phase consists in the development of the framework, its validation and the criteria weight elicitation;

- the choice phase deals with the final validation of the tool and its dissemination. 


\section{INTELLIGENCE PHASE}

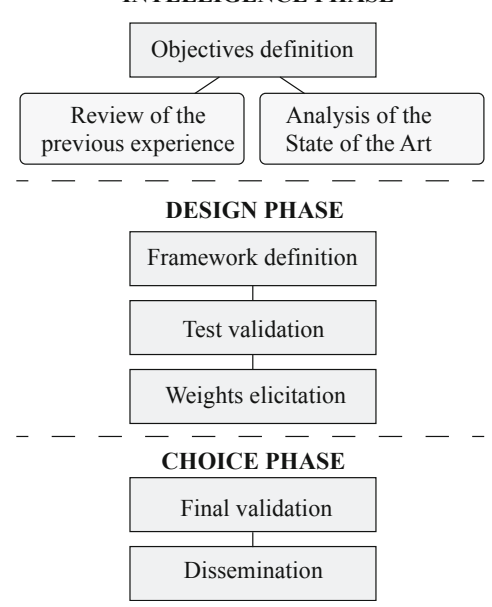

Fig. 1. Methodological flowchart

\subsection{Intelligence Phase}

Given the final objective to support LHAs in formulating suggestions to protect and promote Public Health into urban plans, considering an Urban Health approach, the research started with a deep analysis of the State of the Art. This step consisted of a literature review with special reference on Experience Based Healthy Design and Urban Planning Strategies, the analysis of existing urban-scale assessment tools and the revision of case studies of urban regeneration with health impacts on the context.

The literature confirmed the suitability of the MCA in supporting decisions about complex problems since allows to structure them in hierarchical phases and levels in order to be solved by having an overall view of the big picture. In particular, problems concerning the transformation of the environment are defined as complex [6], since they are characterized by a multidimensional nature where multiple trade-offs have to be found among several aspects. It is therefore essential to evaluate their impacts and effects on the environmental quality and the social well-being in order to guarantee transparency and legitimacy of those processes whose final decision is able to affect the entire community. In this context the transparency is ensured by the adoption of clear methodologies able to guide the decision-makers in the different phases of the evaluation process $[11,12]$.

Moreover the comparison with literature allowed to identify the most frequently used and validated assessment tools aimed to evaluate urban quality and sustainable features of urban projects and plans [Green Star Communities, Australia; Global Sustainability Assessment System (GSAS), Qatar; Comprehensive Assessment System for Built Environment Efficiency for Urban Development (CASBEE-UD), Japan; LEED Neighbourhood Development, United States; British Research Establishment Environmental Assessment Method for (BREEAM) Communities, United Kingdom; DGNB System, German Sustainable Building Council; HQE for Urban Planning Development (UPD), France]. From the analysis and comparison of the related indicators, it has been pointed out, in most of them, the absence of specific criteria directly connected to Public Health outcomes [13]. 


\subsection{Design Phase}

The previous phase led to the definition of criteria and indicators able to measure to which extent a town-planning plan is able to promote Urban Health strategies and to enhance a built environment aimed at satisfying social needs, improve people's quality of life and promote the adoption of healthy lifestyles, like Physical Activity.

Most of the criteria are a review of those defined during the previous experience [6] while others are the result of emerging needs reported by studies on Urban Health and Experience Based Healthy Design [14]. Moreover, within this context, the Multicriteria Analysis (MCA) has been considered as the most suitable methodology able to face the complexity of the decision context given by the presence of several and sometimes conflictual objectives and the co-existence of different dimensions to balance.

The framework underwent two different steps to achieve the final validation. The first moment involved the application of the multicriteria tool on existing urban plans and it has been carried on by the LHA of Bergamo, divided in two teams of professionals. Within this first step, a special attention has been given to the evaluation of the effectiveness of the tool and its objectiveness in formulating judgements. The second moment consisted in two meeting organized with the Welfare General Directorate of Lombardy Region and professionals coming from all the LHAs based in Lombardy Region, in order to have feedbacks about the tool.

Once all the feedbacks have been collected and processed, the final framework has been defined composed by 20 criteria (indicators), aimed to assess the propensity of urban plans to promote Urban Health strategies. The criteria are divided into 7 macroareas: the first one including prerequisites ( 0 . General criteria) while the other 6 constituting the assessment tool (1. Environment; 2 . Soil and subsoil; 3 . Sustainability and hygiene of the built environment; 4. Urban and social development; 5. Mobility and transport; 6. Outdoor spaces).

- Based on an idea of urban quality that diverges - significantly - from the traditional quantitative type, linked to the concept of urban planning standards, the proposed criteria are qualitative and performance. Each criteria is then assessed through a performance matrix. The attribution of the judgment to the criteria consists in verifying the level of adhesion of each urban plan/project to a set of performance requirements (presence/absence of specific Urban Health strategies) described in the matrix, according to the following scheme: Strong: it represents the performance most consistent with the objectives of Urban Health, with reference to the single criterion analyzed;

- Moderate: it is the intermediate level and refers to a consistent performance that can be improved;

- Low: it does not consider any Urban Health strategy, limiting itself to mere compliance with sector regulations.

The individual judgments correspond to numerical values in order to elaborate summary evaluations (evaluation by areas and the final overall evaluation of the project) and explanatory graphs of analysis.

When the final set of indicators has been structured (Fig. 2), it has been possible to weight their influence in achieving the main objective. 


\begin{tabular}{|c|c|}
\hline pre-Requisites & check-list \\
\hline \multirow{4}{*}{$\begin{array}{l}\text { GENERAL } \\
\text { CRITERIA }\end{array}$} & Demographic and epidemiological data \\
\hline & Indoor and Outdoor coherence \\
\hline & Forecasting building capacity \\
\hline & Land destination (in term of urban functions) \\
\hline MACRO-AREAs & CRITERIA \\
\hline \multirow{4}{*}{ ENVIRONMENT } & $01-$ Air and Smells \\
\hline & 02 - Water \\
\hline & 03 - Noise (acoustic pollution) \\
\hline & 04 - Ionizing and non-ionizing radiation \\
\hline \multirow{4}{*}{$\begin{array}{l}\text { SOIL \& } \\
\text { SUBSOIL }\end{array}$} & 05 - Land consumption \\
\hline & 06 - Soil permeability and Water Management \\
\hline & 07 - Geological, hydro-geological and seismic risk \\
\hline & 08 - Contaminated sites and areas with high environmental risk \\
\hline \multirow{3}{*}{$\begin{array}{c}\text { SUSTAINABILITY } \\
\text { \& HYGIENE OF THE } \\
\text { BUILT ENVIRONMENT }\end{array}$} & 09 - Solid waste collection \\
\hline & 10 - Urban waste collection and disposal \\
\hline & 11 - Energy and reduction of emissions \\
\hline \multirow{3}{*}{$\begin{array}{l}\text { URBAN \& SOCIAL } \\
\text { DEVELOPMENT }\end{array}$} & 12 - Residential density \\
\hline & 13 - Functional and Social mixitè \\
\hline & 14 - Universal Design and Social inclusion \\
\hline \multirow{3}{*}{$\begin{array}{l}\text { MOBILITY \& } \\
\text { TRANSPORT }\end{array}$} & 15 - Street infrastructure network and parking system \\
\hline & 16 - Public transportation \\
\hline & 17 - Pedestrian and Cycling path system \\
\hline \multirow{3}{*}{$\begin{array}{l}\text { OUTDOOR } \\
\text { SPACES }\end{array}$} & 18 - Outdoor space system \\
\hline & 19 - Urban green system \\
\hline & 20 - Lighting and visual comfort \\
\hline
\end{tabular}

Fig. 2. Assessment framework

In fact, considering the aim of evaluating the willingness of a town-planning plan to promote Urban Health, the SWING method has been selected as the most appropriate technique since explicitly incorporates the attribute ranges in the elicitation question [15]. In particular, it uses a reference scenario in which all the attributes get their worst level and the interviewee is asked to score (e.g. in the range 0-100) the scenarios in which one attribute at a time changes its status and moves to the best level. The weights are then elaborated and are proportional to the values assigned. For this phase experts of Politecnico di Milano and professionals from LHA have been involved.

\subsection{Choice Phase}

Once the multicriteria tool has been framed and weighted, it has been presented to a multi-disciplinary panel of experts with the role of final reviewers of the methodology applied and the contents described. Following the positive feedbacks received from the panel, the tool has been further integrated, so to better describe and explore some methodological steps. Finally, the tool was presented in public to potential 
Stakeholders (urban planners, designers, Public Health experts, Policy Makers, Administrators, etc.) in order to identify any further aspects to be improved and to have an additional validation.

The LHA of Bergamo, local research unit of the CCM2017 Project, tested the assessment framework in its daily activities of urban plans and projects' evaluation. This approach, common to all the Public Health operators, will be helpful to be more effective and incisive in the opinions to be expressed about urban plans and projects, with a carefulness to the design sphere that consider more strategic the performances and that exceeds compliance with regulatory requirements. At the same time, designers can receive an effective support about the application of Urban Health strategies, inherent the wording of the framework indicators. The assessment framework has therefore been validated and the dissemination phase of which manuals, papers and workshops are part, has begun.

\section{Evaluating the Built Environment}

Within this context, as it has been already described, the multicriteria framework allows to give an overall evaluation of urban plans according to the Urban Health approach by considering external and design factors. What deserve to be explored is the role of the built environment in promoting or negatively affecting the wellbeing of inhabitants. In fact, among the selected macro-areas, one is focused in analyzing the role of buildings and the design process in achieving sustainable goals.

\subsection{Sustainability and Hygiene of the Built Environment}

The third macro-area, titled "Sustainability and hygiene of the built environment", is the which one that involves all the indicators aimed at assessing the possible interactions (positive or negative) of urban plans on the environment in terms of sustainable development and resilience to climate change. Here both the management dimension and the design one are considered. In fact, the first criterion 09 - Solid waste collection consider all policies aimed at managing the entire waste process, from its production to its final outcome. Innovative systems of waste collection, like pneumatic networks, have direct impacts on hygiene, cleaning and sanitation actions of the city and its public spaces, whether they are close to residential dwellings [16], or closer to squares and public spaces in general. The criterion is also focused on the process of collection, transport, treatment (recovery or disposal) and also the reuse of waste materials, usually produced by human activity, in an attempt to reduce their effects on human health and the environment. The second one, 10 - Urban waste collection and disposal considers the infrastructure or sewerage network as a complex and articulated system of underground canalizations that allows the collection and conveyance of domestic, industrial and urban wastewater. This wastewater is then purified and discharged into river mouths or directly into the sea. When disposing of wastewater, a distinction must be made between black water and rainwater (or white water). In order to design sustainable living environments that respect the natural water cycle, it is important to anticipate and encourage the following strategies: a) separate sewerage (rainwater and sewage); b) rainwater reuse system after separation of first rainwater. The last criterion, 
11 - Energy and reduction of emissions encourages greater awareness of consumption and sustainability regarding technological and plant engineering choices in order to improve the energy efficiency of buildings. In fact, the reduction of energy consumption leads to less local air pollution, with direct positive effects on the Public Health of the inhabitants. In addition, lower air pollution leads to lower impacts on the climate-environment, which in turn leads to further lower impacts on health. It is therefore important to reach performance certificate with high performance class or presence of further recognized environmental certification (LEED, BREAM, etc.); or adopt a balance between the following strategies:

- passive principles for sustainability (orientation and shape; thermal insulation and inertia; natural ventilation; shielding systems);

- active principles for sustainability in \% above the legal minimums: (electricity and thermal energy from renewable sources, efficient plant systems).

It is important to underline how the role of humans is fundamental in achieving sustainable objectives even related to their own health, according to the Healthy Cities definition stating that urban settlements are "those urban centers that continuously creating and improving those physical and social environments, encouraging the expansion of resources and making people in conditions to support each other in performing and developing all the daily activities." [17]. All the instances discussed in this macro-area aim at improving the overall quality of life by providing strategies that could be adopted during the design phase.

\section{Conclusions}

This research project could be considered a starting point to disseminate methods, tools and indicators to design (if applied preliminarily to the project by architects and urban planners) and assess (if used from the LHAs) the public spaces' environmental quality, according to the international scenario [20], where several frameworks - mainly conscious about the urban quality assessment - are frequently used, like those one cited in the introduction. The research and application outlooks will take consistency in spreading the tool to all the LHAs, but also to the architectural and urban planning firms, in order to be applied - bilaterally - since from the early design stages.

It is necessary and crucial to evaluate the public space with qualitative frameworks and approaches, highlighting the urban context and public spaces features, experiencebased oriented to promote healthy lifestyles.

Making cities healthier means to improve those physical factors - as network of public spaces, land use mix, street design, etc. - capable to create a more healthy, safe, comfortable and attractive places. Making the urban settlements more sustainable means also take care about the built environment, both in the design process and in the building features (construction materials, active and passive solar systems, environmental orientation of buildings; etc.).

The paradigm of Public Health needs to be changed, moving from a medical model, focused on the individuals, to a social model, where the health status is the result of various socio-economic, cultural and environmental factors. 
A multidisciplinary approach is crucial [18-20], as it enable to put together different stakeholders, like epidemiologist and Public Health experts; urban planners, designers and construction technologists; Policy Makers, to enhance a direct interaction with decision-maker; and, finally, economists or valuation experts, dealing with the project feasibility studies.

Acknowledgments. The project development was possible thanks to the funds of the National Center for Disease Prevention and Control CCM2017 regarding the project titled "Urban Health: good practices for health impact assessment of urban and environmental redevelopment and regeneration interventions." (CUP: C42F17000330001) and all the related partners involved, like LHA of Bergamo (Complex Operating Unit in Hygiene and Public Health, Health-Environment), Welfare General Directorate of Lombardy Region and Italian Ministry of Health (Office 8 Health promotion, prevention and control of chronic degenerative diseases).

\section{References}

1. Talukder, S., Capon, A., Nath, D., Kolb, A., Jahan, S., Boufford, J.: Urban health in the post2015 agenda. Lancet 385, 769 (2015). https://doi.org/10.1016/S0140-6736(15)60428-7

2. Capolongo, S.; Buffoli, M.; Brambilla, A.; Rebecchi, A.: Healthy urban planning \& design strategies to improve urban quality and attractiveness of places. In: TECHNE 19 TOPIC 2: The Public Space as Environmental Infrastructure, Functional to the Pursuit of Urban Sustainability Goals (in press)

3. Sustainable Development Commission: Health, Place and Nature. How Outdoor Environments Influence Health and Well-Being: A Knowledge Base (2008). https://researchrepository.st-andrews.ac.uk/handle/10023/2180

4. World Health Organization: Health as the Pulse of the New Urban Agenda (2016). http:// apps.who.int/iris/bitstream/handle/10665/250367/9789241511445-eng.pdf;jsessionid= 07F882D99F1E1AF399B57D5546EEB2BB? sequence $=1$

5. Gianfredi, V., Balzarini, F., Gola, M., Mangano, S., Carpagnano, L.F., Colucci, M.E., Gentile, L., Piscitelli, A., Quattrone, F., Scuri, S., Mantovani, L.G., Auxilia, F., Castaldi, S., Capolongo, S., Pelissero, G., Odone, A., Signorelli, C.: Leadership in public health: opportunities for young generations within scientific associations and the experience of the "Academy of Young Leaders". Front. Public Health 7, 378 (2019).https://doi.org/10.3389/fpubh.2019.00378

6. Capolongo, S., Buffoli, M., Mosca, E.I., Galeone, D., D'Elia, R., Rebecchi, A.: Public health aspects' assessment tool for urban projects, according to the urban health approach. In: Della Torre, S., Cattaneo, S., Lenzi, C., Zanelli, A. (eds.) Regeneration of the Built Environment from a Circular Economy Perspective. RD, pp. 325-335. Springer, Cham (2020). https://doi. org/10.1007/978-3-030-33256-3_30

7. Capolongo, S., Sdino, L., Dell'Ovo, M., Moioli, R., Della Torre, S.: How to assess urban regeneration proposals by considering conflicting values. Sustainability 11(14), 3877 (2019). https://doi.org/10.3390/su11143877

8. Capasso, L., Faggioli, A., Rebecchi, A., Capolongo, S., Gaeta, M., Appolloni, L., De Martino, A., D'Alessandro, D.: Aspetti igienico-sanitari in ambito urbanistico: Conflittualità nelle norme urbanistiche nazionali e locali in tema di Sanità Pubblica. Epidemiol. Prev. 42, 60-64 (2018)

9. Capolongo, S., Rebecchi, A., Dettori, M., Appolloni, L., Azara, A., Buffoli, M., Capasso, L., Casuccio, A., Oliveri Conti, G., D'Amico, A., et al.: Healthy design and urban planning strategies, actions, and policy to achieve salutogenic cities. Int. J. Environ. Res. Public Health 15, 2698 (2018) 
10. Simon, H.A.: The New Science of Management Decision. Harper and Row, New York (1960)

11. Rebecchi, A., Buffoli, M., Dettori, M., Appolloni, L., Azara, A., Castiglia, P., D’Alessandro, D., Capolongo, S.: Walkable environments and healthy urban moves: Urban context features assessment framework experienced in Milan. Sustainability 11(10), 2778 (2019). https://doi. org/10.3390/su1110277

12. Bouyssou, D., Marchant, T., Pirlot, M., Perny, P., Tsoukias, A., Vincke, P.: Evaluation and Decision Models. A Critical Perspective. Springer Science \& Business Media, New York (2000). https://doi.org/10.1007/978-1-4615-1593-7

13. D'Alessandro, D., Appolloni, L., Capasso, L.: Public Health and urban planning: a powerful alliance to be enhanced in Italy. Ann. Ig. 29, 452-463 (2017). https://doi.org/10.7416/ ai. 2017.2177

14. Ferretti, V., Bottero, M., Mondini, G.: Decision making and cultural heritage: an application of the Multi-Attribute Value Theory for the reuse of historical buildings. J. Cult. Herit. 15(6), 644-655 (2014)

15. Gola, M., Signorelli, C., Buffoli, M., Rebecchi, A., Capolongo, S.: Local health rules and building regulations: a survey on local hygiene and building regulations in Italian municiples. Ann. Istituto Superiore di Sanità 53(3), 223-230 (2017). https://doi.org/10.4415/ ANN_17_03_08

16. Rydin, Y., Bleahu, A., Davis, M., Dávila, J.D., Friel, S., de Grandis, G., Groce, N., Hallal, P. C., Hamilton, I., Howden-Chapman, P., et al.: Shaping cities for health: Complexity and the planning of urban environments in the 21st century. Lancet 379, 2079-2108 (2012)

17. World Health Organization: International Workshop on Housing, Health and Climate Change: Developing Guidance for Health Protection in the Built Environment Mitigation and Adaptation Responses (2010). http://www.who.int/hia/house_report.pdf. Accessed 20 Sep 2019

18. Oppio, A., Bottero, M., Giordano, G., Arcidiacono, A.: A multi-methodological evaluation approach for assessing the impact of neighbourhood quality on public health. Epidemiol. Prev. 40, 249-256 (2016)

19. Capolongo, S., Lemaire, N., Oppio, A., Buffoli, M., Roue Le Gall, A.: Action planning for healthy cities: the role of multi-criteria analysis, developed in Italy and France, for assessing health performances in land-use plans and urban development projects. Epidemiol. Prev. 40, 257-264 (2016)

20. D'Alessandro, D., et al.: Strategies for disease prevention and health promotion in urban areas: the Erice 50 Charter. Ann. Ig. 29, 481-493 (2017)

Open Access This chapter is licensed under the terms of the Creative Commons Attribution 4.0 International License (http://creativecommons.org/licenses/by/4.0/), which permits use, sharing, adaptation, distribution and reproduction in any medium or format, as long as you give appropriate credit to the original author(s) and the source, provide a link to the Creative Commons license and indicate if changes were made.

The images or other third party material in this chapter are included in the chapter's Creative Commons license, unless indicated otherwise in a credit line to the material. If material is not included in the chapter's Creative Commons license and your intended use is not permitted by statutory regulation or exceeds the permitted use, you will need to obtain permission directly from the copyright holder.

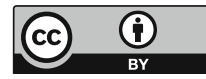

